\title{
Smart business networks: architectural aspects and risks
}

\author{
L-F Pau
}

\begin{tabular}{|l|l|}
\hline \multicolumn{2}{|l|}{ ERIM REPORT SERIES RESEARCH IN MANAGEMENT } \\
\hline ERIM Report Series reference number & ERS-2004-079-LIS (Business Telecom Pau) \\
\hline Publication & August 2004 \\
\hline Number of pages & 14 \\
\hline Email address corresponding author & Ipau@fbk.eur.nl \\
\hline Address & Erasmus Research Institute of Management (ERIM) \\
& Rotterdam School of Management / Rotterdam School of \\
& Economics \\
& Erasmus Universiteit Rotterdam \\
& P.O. Box 1738 \\
& 3000 DR Rotterdam, The Netherlands \\
& Phone: +31 104081182 \\
& Fax: +31 104089640 \\
& Email: info@erim.eur.nl \\
& Internet: www.erim.eur.nl \\
\hline
\end{tabular}

Bibliographic data and classifications of all the ERIM reports are also available on the ERIM website: www.erim.eur.nl 


\section{ERASMUS RESEARCH INSTITUTE OF MANAGEMENT}

REPORT SERIES

\section{RESEARCH IN MANAGEMENT}

\begin{tabular}{|c|c|c|}
\hline \multicolumn{3}{|c|}{ BIBLIOGRAPHIC DATA AND CLASSIFICATIONS } \\
\hline Abstract & \multicolumn{2}{|c|}{$\begin{array}{l}\text { This paper summarizes key attributes and the uniqueness of smart business networks [1], to } \\
\text { propose thereafter an operational implementation architecture. It involves, amongst others, the } \\
\text { embedding of business logic specific to a network of business partners, inside the } \\
\text { communications control networks .It also involves the definition of business protocols between } \\
\text { these partners and the joint management of some common functions relying on open networking } \\
\text { standards. This implies some key paradigm changes, both of a technical and of a business } \\
\text { nature, which are offered here for discussion via a set of propositions. }\end{array}$} \\
\hline \multirow{3}{*}{$\begin{array}{l}\text { Library of Congress } \\
\text { Classification } \\
\text { (LCC) } \\
\text { http://lcweb.loc.gov/catdir/cps } \\
\text { o/lcco/lcco_h.pdf }\end{array}$} & \multicolumn{2}{|l|}{ Mission: HF 5001-6182 } \\
\hline & \multicolumn{2}{|l|}{ Programme: HE 9713+ } \\
\hline & Paper: HD $69 . S 8$ & Business Networks \\
\hline \multirow{4}{*}{$\begin{array}{l}\text { Journal of Economic } \\
\text { Literature } \\
\text { (JEL) } \\
\text { http://www.aeaweb.org/journ } \\
\text { al/jel_class_system.html }\end{array}$} & \multicolumn{2}{|l|}{ Mission: M } \\
\hline & \multicolumn{2}{|l|}{ Programme : L 63, L 96} \\
\hline & \multirow{2}{*}{$\begin{aligned} \text { Paper: } & \text { L } 63 \\
& \text { L } 14\end{aligned}$} & Communication equipment \\
\hline & & Networks \\
\hline \multicolumn{3}{|c|}{ Gemeenschappelijke Onderwerpsontsluiting (GOO) } \\
\hline \multirow[t]{3}{*}{ Classification GOO } & \multicolumn{2}{|l|}{ Mission: 85.00} \\
\hline & \multicolumn{2}{|l|}{ Programme: 05.42} \\
\hline & Paper: 05.49 & Communicatietransport: overige \\
\hline \multirow[t]{3}{*}{ Keywords GOO } & \multicolumn{2}{|l|}{ Mission: Bedrijfskunde / Bedrijfseconomie } \\
\hline & \multicolumn{2}{|c|}{ Programme: Draadloze Communicatie } \\
\hline & \multicolumn{2}{|c|}{ Paper: Communicatienetwerken, Innovatie, benchmarking } \\
\hline Free keywords & \multicolumn{2}{|c|}{$\begin{array}{l}\text { Smart business networks, control networks, SS7, P1520, business protocols, mobile business, } \\
\text { network architecture, service level agreements }\end{array}$} \\
\hline
\end{tabular}




\title{
Smart business networks: architectural aspects and risks
}

\author{
L-F Pau \\ Rotterdam School of management, F1-26, Erasmus University, POBox 1738, NL 3000 DR \\ Rotterdam, Netherlands lpau@fbk.eur.nl
}

\begin{abstract}
This paper summarizes key attributes and the uniqueness of smart business networks [1], to propose thereafter an operational implementation architecture. It involves, amongst others, the embedding of business logic specific to a network of business partners , inside the communications control networks .It also involves the definition of business protocols between these partners and the joint management of some common functions relying on open networking standards. This implies some key paradigm changes, both of a technical and of a business nature, which are offered here for discussion via a set of propositions.
\end{abstract}

\section{Introduction to Smart Business networks}

The intelligence of a network is augmented by its functionality - its ability to distribute, store, assemble, or modify information. Transmission networks are technically complex, but business-wise they are “dumb” pipes that transport information without enhancing it. A network augmented by business relationships can be "smart"; it can improve the utility of information in multiple ways. That is synonymous with creating economic value.

This paper is about architectual trade-offs and risks enabling the relationship between the intelligence of networks and the smartness of the businesses that use these networks. Some basic concepts for “smart business networks” (SBN's) have been laid in [1] and possibly in other related best practices [23].

All three words in the title "smart business networks" are necessary . In management , the adjective "smart" is attributed to an action that is novel and different, hence thought of as innovative. Smart actions create remarkable, "better than usual" business results. Smart has a connotation with fashionable and distinguished, but also with short-lived. . The word "smart" in smart business networks is therefore not an absolute but a relative term. Smartness is a property whereby the network can create "better" results than other, less smart business networks or other forms of business arrangements. While intelligence in the communications systems and networks may have a more absolute meaning, smartness of business networks is relative, time-bound and situation-bound. 
The pair of words "smart business" can apply to any business without a network. A "smart network" can apply to a network that is not used for business or organisation. A "business network" is generic and includes both smart and not-so-smart business networks. A “ smart business network” (SBN) is defined , inspired from [1], but defined here more operationally , as:

- A group of participating businesses - organisational entities or “actors" - that form the nodes , and this group is not necessary visible to the outside ;

- Linked together via one or more communication networks forming the links, or lines, between the nodes;

- Linked together as well by a set, possibly ontology based, of bilateral or SBN network wide , agreements or service level agreements (SLA's) of a temporary nature

- Interacting in novel ways they could not implement on their own, or possibly with other parties ; this is the SBN network benefit ;

- Perceived by each participant as increasing his own value ,meaning that while overall goals/utility functions may be different, some can be shared within the network with estimated derived positive benefits ; the basic equilibrium concept is one of a non-cooperative Nash game, and not of a collaborative Pareto game ;

- Sustainable over some time as a network, subject to agreed upon termination rules ;

- Resilient if one or more businesses, nodes in the network, drops out, disappears , or malfunctions.

A “smart business network" is not a rigid physical supply network governed by static agreements ,and described by graph theory alone via a static graph. The networked business environment is fast and agile. Supply trees are selected from the network frequently and rapidly, and they usually have short lifetimes because the commercial or expertise sharing opportunities have short lifetimes. Smart Business Networks develop not only because technology permits them to develop, but more significantly because markets and modern business competitiveness require such networks in order to survive and thrive. Management attention then focuses on managing the network, on the processes for joining or leaving a network, and on processes by which to select supplier trees from the network. . We can now go one stage further and say that the fundamental competitive capability is to construct and manage a smart business network.

Whereas some physical supply networks exhibit the attributes of smart business networks, already today most of their attributs can be found to some extent in ,e.g.: -mobile content delivery networks, where quick-connect must be done in quasi real-time with content /DRM owners at end user request [2, 3] ; -electronic CAD networks, where building blocks get assembled with custom blocks , simulated, tested and prototyped ;

-health management insurance networks where specific expertise in a localized way has to be assembled ogether with service delivery facilities such as clinics Business networks that are smart , display quick connect and quick disconnect capabilities; they can pick the best capabilities from many network actors, plug these 
capabilities together, and make these play in unison; they also control, or own, the business logic for multi-actor execution of business processes.

\section{Smart Business Network Capabilities}

The following capabilities are seen in smart business networks:

- Establishment of common understandings: of meanings, words, ontologies , ethics and informal commitments, and of the principles followed in contractual obligations;

- Membership selection: the capabilities to decide which business entities can act as nodes of the network; it includes a search-and-select behaviour by the actors. Once the appropriate actor, or node, is found, and the connection has been established, the process of performing a business transaction can begin.

- Membership ending rules and procedures over time ; the capability to quickly disconnect, is a process greatly influenced by risk and reward division [4]. This will be a vital element of a smart business network, because unless it is agreed ahead of time how risk and reward will be allocated, serious problems of mistrust can develop ;

- Linking: the positioning and connecting of nodes to the other parts of the network. The linking processes can include the directories (search and select) and routing (path finding) through the network as well as communications infrasttructure elements such as authentication, trust establishment, firewalls , and network management;

- Goal selection and dynamic conflict resolution : the coordination mechanisms that determine the limited shared goals in the business network and the tasks and responsibilities assigned to each member node;

- Interaction and sharing : the shared expertise, management and capabilities that make the network generate novel results, preferably those that no single member could achieve on its own;

- Risk and reward management: the division of material results (profit and loss in a monetary but also know-how, intellectual property rights , customer data ,etc . ) and the perceived value by each of the participating business entities of its share;

- Resilience, fault tolerance/recovery and risk management: risk measuring and distribution rules, and conflict resolution processes ; clearly connections in a smart business network are much more complicated to achieve and require higher levels of mutual trust.

It should be pointed out that experience from business partnerships, as well as the nascent smart business networks mentioned as examples in the previous section ,show that the concept of "pick , plug and play “ advocated for by business modularity theory [5-7],does not create any agregation forces within a smart business network .[8] discerns three dimensions of modularity: product modularity, process modularity, and value chain (business network) modularity. Successful modular design, according 
to [8], should not be restricted to products but must be concurrent in all three dimensions.However ,the specification and agreement on the protocols between modules is so unlikely or risky that, even seen this way, business modularity if detected in a smart business network, will mostly carry the roots of its disapperarance.. Simon [9] gives an important clue: formal process descriptions make us understand the relatively simple, dynamic laws that can change states found in systems such as smart business networks .

In this paper we argue that the drivers for smart business networks (Section 1), coupled above all with the interoperability of the smart business network node's execution networks and environments, enable to reduce duplication in modularized business processes and their support systems, and therefore to run business processes more efficiently and with more flexibility. For example, client authentication and credit checking do not need to be caried twice in the mobile networks and in the banking transactions processing systems, so they can be moved from financial institutions to communication operators or vice-versa [10] . The paper suggests therefore to go with the technical current and to move major elements of business process logic (such as authentication and credit checking) into communication nodes for more flexible and efficient execution. Client behavior and regulatory rules as well as other changes are anticipated..

\section{From business process to business network}

Once process logic can be abstracted from its runtime environment it is possible to divide process modules over a number of different actors - defined as organizational entities - that are connected together via a communications infrastructure (see Figure 1).

Generally, one of the major stumbling blocks to swift process co-ordination in general , is the distribution of business and process logic over actors which all rely on one or several third party communication networks ,sometimes incompatible at least as to application specific interfaces or middleware .

Within the smart business network itself , the architectural question is how to achieve this on-the-fly coordination without relying on third party communications and transactuions provisioning. The business problem of path finding and resource allocation within a smart business network is also very similar to the issues surrounding naming/ addressing/ routing and capacity utilization in traditional communications network design and management.

To cater to the needs of smart business networks, and the completion of their capabilities, this paper endeavours a novel approach to embedding the shared business logic (specific to and within a smart business network), into the control layers of communications networks ,under the control of the smart business network parties [11-12]. 


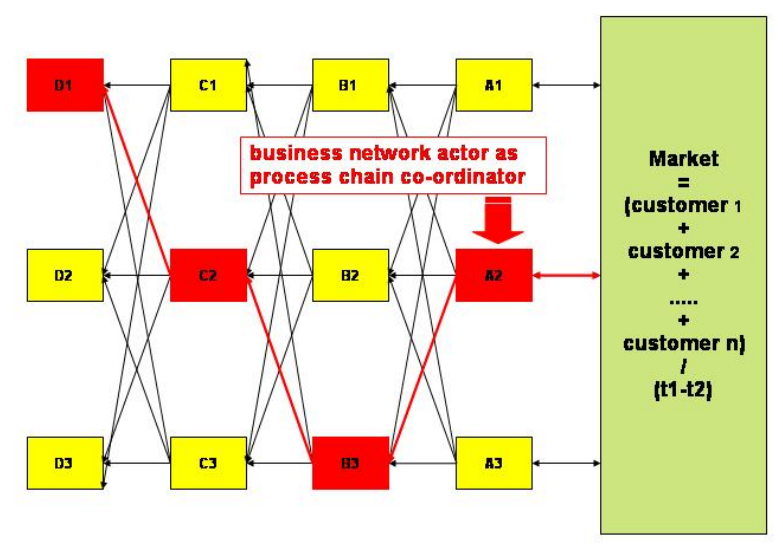

Fig. 1. Each smart business network actor pledges process modules (defined as service elements and production elements) that can be linked together to satisfy a defined customer order ].

\section{The business Process impact of on-the-fly user-driven management of smart business network support architectures}

What is specifically proposed to enable smart business networks, is to use the control network to carry business protocols and fulfillment / settlement between members in smart business networks ,while maintaining the tight separation control networks have been built around [11]. The control networks already ensure interoperability between the information \& communication networks of the members in a smart business network .But it is quite possible to use the control communication networks, for yet another purpose, which is the coordination of smart business network processes, their synchronization,and the transport functions needed by the business protocols the smart business network members have agreed to use between themselves .

There are however legacy considerations to be taken into consideration, as the use of these control networks by the parties themselves require freedom to do so .

\subsection{Transport and signalling networks}

What has been little realized outside technical circles within communications equipment suppliers or communication service suppliers, is that historically voice and data flows have obeyed two underlying design principles: 
a) the separation of transport and content (voice, data), although specific protocols and quality of service can regulate properties of the flows based on the application requirements; today this extends to the regulatory definition of backbone network operators and access network operators on one hand, and content providers on the other hand;

b) the separation of the transport networks from the control networks, which allow to set-up, manage, close and record the characteristics of connections or communication sessions; such control networks are often, for availability and security reasons physically separate from the transport networks, and execute control functions in a connection based or connection less way (SS7 and its equivalent for ATM networks in the first case, TCP in the second case, and SCTP as an intermediate solution ) ${ }^{1}$.

However, because obviously a control network is required to run and get revenue from a transport network, the ownership of the two was traditionally the same, and thus the suppliers were traditionally supplying integrated transport and control networks with management thereof. Operators could embed via application-specific programming of the upper SS7 stack layers (MTP-3), so called "intelligent network" or "computational intelligence " functionality, such as call admission control, mobile agents, etc...(see e.g. [13]).

From the business process management point of view, the interest is not on the transport networks, but on the capabilities offered by the signalling/control networks by extending their functionality, with due separation,to carry business protocol and coordination traffic . Admittedly, SS7, SCTP management exclusively by the operators gave them too much power in process managementby making it impossible to make such as use of the signalling networks .

\subsection{Open signalling and adaptive networks}

From a technical and research perspective, things have changed with standards such as SIP and the IEEE P1520 standards [14-15] for interfaces to communication networks which are not just circuit switching based (ATM, IP), as well as so called adaptive networks. Both define interfaces such that a user, e.g. the economic agent initiating a transaction inside or outside a smart busines network, can determine the controls applicable to his own communication needs (connection, session, flow), and choose between transport networks or their dynamic configurations

From the business process management point of view, it should be possible to extend the IEEE P1520 programmable interfaces to networks and/or SIP, with corresponding programming model and binding mechanisms, to business logics and not just tariffs or quality of service.

\footnotetext{
1 The Stream Control Transmission protocol SCTP allows companies to exchange signalling information between switching systems using IP
} 


\subsection{Hot billing and pre-paid services:}

Whereas traditionally subscription based fixed or mobile voice and data services rely on the delayed payment to the operator of both interconnect ,transit and traffic charges , via payment intermediaries, hot-billing and pre-paid platforms have changed the fundamental synchronisation of business transaction fullfillment . The need to check the outstanding balance of a customer (or a cross charge to an internal smart business network cost center) prior and during a call or transaction, have shifted the ultimate solvency testing of the end user away from the payment intermediary over to the mobile operator and it's associated rating systems. Communications equipment providers have thus engineered interface and control systems which link directly the control network (which establishes the connection or session) with the customer care system (which checks on prepaid balances), all this in real time. What this means, is that from being traditionally trusted with the collection, aggregation, and solvency checks of the end user, the payment intermediary has only the collection task left. This turns the mobile operators into having the technical capability to verify and settle internal transactions within a smart business network,and possibly (subject to authentification , security and risk provisioning) into a similar capability vis-a-vis customers of the smart business network .

As to the end user authentification, it is still split and essentially done twice in different ways, because of different processes for authentification on the communications service provisioning side of the operator (typically AAA servers), and for the payee authentification of the payment intermediary (typically a financial collection system with account identification and authentification).

From the point of view of business process management, hot billing illustrates alltogether the ability of non-payment agents to take on financial deposits and collection management, and even to extend this to other services, while managing the communication networks at the same time. Pre-paid services also illustrate the ability in mobile networks to activate and monitor service level agreements between parties in real time. 


\section{Embedding the business logics into the communication networks}

\subsection{A communications-enabled business architecture}

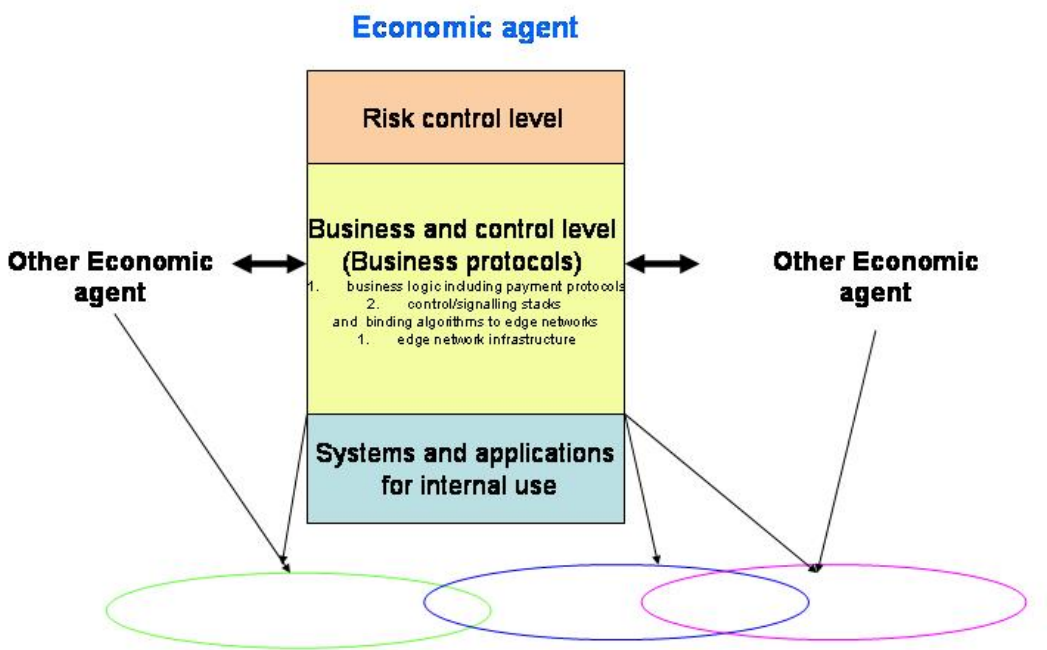

Alternative transport networks

Fig. 2. Economic agent which interacts with other economic agents without general trade and payment intermediaries; this agent has imported into its communications and computer systems the network control functions, and merged these with his own business logic and processes (trade, payment, ERP, etc...)

Figure 2 shows how communication networks can provide a basic business architecture, with:

-a transport and capacity level, which is a technical agent chosen by the next level up;

-a business and control level at which an economic agent determines his business logic around the information, transport and services he needs, to select and control the transport level; this level interfaces with enterprise internal systems and information;

-a verification and risk control level, where business logic vets and activates the control level.

The technical nodes and business logics or protocols, as well as the interfaces supporting this are defined and discussed below. 


\subsection{Combination of network control logic with business logics/processes: the proposition}

Based on the above, we propose here, and formulated here first in business terms, to embed the business logics and processes of each economic agent into the Business and control level of that Economic agent's control Node in the communications networks at the edges (see Figure 2). Said in other words, but now formulated from a communications point of view, each economic agent would install the interfaces and control software of communication networks, and combine these with his own business logics and processes on both the trade and payment sides [11-12].

This is of course only possible, in terms of genericity and availability of the corresponding software, for those elements of the network control, trade processes and payment processes, which are best practices in each case - This implies of course that only specialized trade or payment intermediaries which have proprietary interfaces and processes, will co-exist with the economic agents initiating transactions, as the bulk of standardized processes will bypass them.

Figure 2 also highlights that, whereas all economic agents have engineered a possible choice of transports to support their needs at transport level, some of these may be shared between economic agents who interact. This is obviously the case both for communication carriers, ISP's as well as transport/logistics networks. However, the economic agent who initiates the transaction or business may, from his own business and control level, retain some control over such transport level resources.

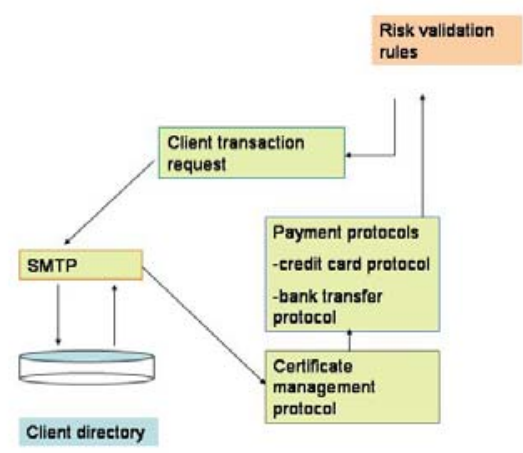

Fig. 3. Example of a business control protocol (parts in green, interacting with internal system in grey and risk control level in brown) enabling a payment process in combination with the SMTP network control. This Figure does not give the detailed flow of interactions between parties, but only aggregates thereof

Transport networks and the network controls for these are unaffected, except that binding interfaces or active network features resident at the economic agent's premises would interface with them. However, it is also possible, at the lower protocol level, to embed and integrate as well detailed transaction rules inside or alongside new application protocols, called "business protocols"; this is illustrated 
here in Figure 3.The business protocols are either specified via BPML language or via UML.

\section{Smart business network architectural elements}

While workflows define how a process should run, the business logic enacts, monitors and controls the process flow in the technical environments of each of the smart business network actors; where necessary it passes control over to external systems to perform a task. This logic is controlled by business rules that take decisions on events depending on the state of the various machines and processes linked to it. There are two critical components to this: the monitoring of all resources in the smart business network, and management through the equivalent of, or rule-based event-correlation. It checks the events it receives against the current rules and "fires" the rules when their conditions are met.

This leads to the selection of the key components of the architecture supporting a smart business network internally as well as externally, at the operational level A , after the management decisions supporting its capabilities:

a1.a common and unique authentification capability with full trust support by all smart business network parties;

a2.a common set of external suppliers and customers interfaces supporting both order handling, classification , payment , certification , fulfillment , SLA's etc..; typically this would be enabled by the selection of an e-Commerce platform or a set of standards by all the smart business network members, such as OMG's MDA , Service oriented computing SOC , or Webservices described in W3C's WSDL (on top of SOAP) ;

a3. the joint adoption of programmable interfaces to the control networks (offered by one or several transport infrastructure providers ), such as IEEE P1520, SIP or equivalent ,for the execution of the business protocols (see explanations in Section 5 ) inside the smart business network ; the combination of these interfaces and of the underlying control networks used, can be called the business control network of the smart business network ; please observe that if ad-hoc or active network [16] controls are applied , this element a3. should still apply

a4. management principles, operating procedures, and technical support as to naming services (OMA), catalogs and directories (eg. via LDAP or equivalents), which however remain under control of each smart business network member;

a5. the set of smart business protocols (see explanations in Section 5 ) shared by the smart business network members for their internal use, and some for use towards joint customers , suppliers or infrastructure/tools / capabilities providers .; these protocols pulled together with their initiatiation/activation conditions constitute the rule-based event correlation

a6. a distributed smart business network monitoring tool, restricted to operate on the jointly shared business control network, and with equal access to the monitoring actions to all smart business network members (duly authentified); this monitoring 
tool should not just be a traffic and alarm handling tool, but much more importantly a toll giving status of the use and execution of the business protocols

On top of the above operational layer, two layers must exist (not discussed here, but in [1]):

B.Management of an individual business - described in a networked systems concept as asset and event management;

C. The dynamic control and governance of the business network.

The creation of logic by individual actors in the business networks takes a new meaning once this is linked together and managed through business protocols, independent of the originating actor(s). Whereas some look at this capability as a "business operating system" [1] for tight coordination , this is not supported here as it is not likely that a monolithic and identical "business operating system" will be viewed as supporting ultimate smart business network partner identity/ independence , nor the agility this network must exhibit . The architecture proposed above on the other hand, while only exhibiting looser coordination, does not preclude other processes and controls to operate within each smart business network partner, and does not either force him to change his own operating and organizational environment: it is a much more network focussed view as opposed to a centralized view of the smart business network operations. The portability of business processes is still possible as well as the end-to-end management thereof.

\section{Business and process management implications of embedding business logic inside the smart business networks (propositions for discussion)}

Embedding the business logic inside the networks, with on-the-fly identification, selection, and management imply several consequences:

Proposition 1: End users members of a smart business network can manage some processes to their liking and for competitiveness, whereas in the past they had to use at best commodity service specifications.

Proposition 2: Potentially a major competition will take place between those backbone operators/network owners offering end users business logic embedding mechanisms, those who do NOT offer this capability, and those who want to set and manage the business logic deployment on behalf of the smart network business members as a managed service.

Proposition 3: New type of real-time business processes and services will become possible (e.g. document and order process synchronization, linking with company archives, project review and auditing across organizations), paving the way to realtime service level agreements and order fulfillment across several partners ([3]).

Proposition 4: Relying on Proposition 3, new type of on-the-fly reverse auctions will become possible (with multivariate attributes and constraints) (see [17]) and will be executed inside the network without relying on a third party. 
Proposition 5: Whereas now the execution of a business processes across several parties is done relying on a neutral set of actors (network providers, data storage providers, ASP's, authentification centers, etc), the neutrality of which can sometimes been put in doubt, the proposed architecture would imply that groups of parties take control of their support nodes; this of course assumes changes to regulatory frameworks in some cases (e.g. granting communication licences to logistics or payment agents).

Proposition 6: New insurance, risk management and legal frameworks are needed to support embedding business logics inside the networks.

\section{Risks involved in smart business networks and some research challenges}

This paper investigates a novel way to embed business logic into the control layers of communications networks at the edges of the backbones. This is motivated e.g. by initial encouraging work at the Rotterdam School of Management in the field of logistics, wireless, and content distribution networks.

Also, as process events can be linked very quickly, and economic agents may recompose themselves and/or their functions, the dynamic resource optimization across many economic agents will be increasingly complicated. We suggest that some genetic and bio-informatics algorithms are useful to realize the corresponding adaptation selection and recalculations of the business logic embedded at the communications level [18-19].

Smartness may emerge spontaneously and not be intentionally designed, and conversely if designed smartness may not deliver its promises and even enhance some business risks. While much theoretical and experimental research is still needed to identify the causal relations leading to smart business network risk formation, some of the underlying forces are the following:

- Bounded group rationality that limits the actors' group mind share in a same way as for individuals [20]. Measurements suggest that not only individual human beings are limited by an inability to digest intense input of data: a group of people, or a network of nodes, show comparable limitations;

- Dynamic emergence and decay of key information brokers, information creators, and information users. Measurement on networks shows that most nodes can be categorised as one of these three types;

- Lack of agreed upon and transparent confidence and trust maintenance procedures

- Changing behaviors due to the networking itself ; cases have already shown [21] that when a company organized itself as a smart business network, it ultimately disappeared as the entities felt their accountability, initiatives ,discipline, focus and expertise did not require the same attention as this was "taken care of by others in the network” 
- What should be the granularity of the operations at each smart business network member when networked ; too high granularity leads to overlaps , inefficiencies and conflicts, while too low granularity reduces innovation and flexibility ; the notion discussed here is not the one of modularity in a linearized supply chain, but the scope of the activities at each business partner in a smart network , which can be formalized by task graph decomposition within a network .

Finally, such an approach opens the way technically to individualized communications tariffs and process costs or each agent, with settlement not only by operators or financial institutions [22].

\section{References}

[1] P.Vervest, E. Heck, K.Preiss , L-F Pau (Eds) , “Smart business networks" , Springer Lecture Notes in computer science , Springer , 2004 , www.springer.de/comp/lcs

[2] L-F Pau , "The real financial challenges of mobile operators, and their business service architecture recomposition”, INNOVATION , World Scientific Press , Vol 4 , no 1 , 2004, p. 56-57, www.innovationmagazine.com

[3] L-F Pau, Real time SLA provisioning for mobile operators needing spontaneously userdefined content, Research report Rotterdam School of management and Open Group QoS Task force, www.opengroup.org/qos_taskforce, 2003

[4] S.L. Goldman, R.N.Nagel, K Preiss, Agile Competitors and Virtual Organizations: Strategies for Enriching the Customer, Van Nostrand Reinhold, New York ,1995

[5] R.A. Garud, R.N.Kumaraswamy, R. Langlois, Managing in the Age of Modularity: Architectures, Networks, and Organizations, Blackwell Publishers, Malden USA, 2003.

[6] M.A. Schilling, Toward a General Modular Systems Theory and Its Applications to Interfirm Product Modularity, Academy of Management Review, Vol. 35, No.2, 2000 , pp. 312-334.

[7] C.Y.Baldwin, K.B. Clark, Design Rules: The Power of Modularity, The MIT Press, Cambridge, Massachusetts, 2000.

[8] M.J. Wolters, The Business of Modularity and the Modularity of Business, ERIM Pd.D. Series in Management, Nr. 11, Trail Thesis Series T2002/1, The Netherlands, TRAIL Research School.

[9] H. Simon, H., The Architecture of Complexity, Proceedings of the American Philosophical Society, No. 106, 1962, pp. 467-482.

[10] L-F Pau , "Mobile operators as banks or vice-versa and: the challenges of Mobile channels for banks “, ERIM Research report ERS-2004-015-LIS , January 2004 http://hdl.handle.net/1765/1663 ; and : Proc. 3 rd Austin Mobility Roundtable , Austin , TX, 1012 March 2004

[11] L-F Pau , P.H.M. Vervest , "Network based business process management : a discussion on embedding business logic in communications networks “, in : J. Grundspenkis , M.

Kirikova (Eds), Proc. CAISE 04 Knowledge and model driven information systems engineering for networked organisations , 16 th Conference on advanced information systems , Riga, 7-11 June 2004 , ISBN 9984-9767-2-6 , pp176-183

[12] L-F Pau , P.H.M.Vervest, "Embedding business logic inside communications networks : a network based business process management”, in : P.H.M.Vervest, E. Heck, K. Preiss , L-F 
Pau (Eds), "Smart business networks", Springer Lecture series in Computer science , 2004 , 15 p. , www.springer.de/comp/lcs

[13] W. Pedrycz, A.Vasilakos, Computational intelligence in telecommunications networks, CRC Press, Boca Raton, 2001, ISBN 0-8493-1075-X

[14] IEEE Standard P1520 Programming interfaces for networks, IEEE Standards Association, 2000

[15]A.Lazar, Programming telecommunications networks, IEEE Network, september/october 1997, 8-18

[16] GCAP Project, EU Framework 4 program, www.cordis.lu, 2000

[17] S. Meij,L-F Pau, L-F; E. van Heck, Auctioning bulk mobile SMS/MMS messages, 2 nd International conference M-Business 2003, Vienna, www.mbusiness2003.org, 2003

[18] J.H. Holland, Genetic algorithms, Scientific American, Vol 278, no 1, 66-72, 1992

[19] N.M. Alemdar,S.Sirakaya, On line computation of Stackelberg equilibria with synchronous parallel genetic algorithms, J. of economic dynamics and control, Vol 27, 15031515, 2003

[20] H.A. Simon, H.A.,The Sciences of the Artificial, The MIT Press, Cambridge, Massachusetts ,1969

[21] C. Ciborra, Innovation, networks and organizational learning (the Olivetti case) , in C.Antonelli (Ed) , The economics of information networks, Elsevier, Amsterdam, 1992, pp 91102

[22] L-F Pau, The communications and information economy: issues, tariffs, and economic research areas, J. Economic dynamics and control, Aug 2002, Vol. 26, nos 9-10, 1651-1676

[23] CISCO,"Productivity best practices” , Executive thought leadership Newsletter , Vol 1 , no 2, 2004 


\section{Publications in the Report Series Research* in Management}

\section{ERIM Research Program: "Business Processes, Logistics and Information Systems"}

\section{4}

Smart Pricing: Linking Pricing Decisions with Operational Insights

Moritz Fleischmann, Joseph M. Hall and David F. Pyke

ERS-2004-001-LIS

http://hdl.handle.net/1765/1114

Mobile operators as banks or vice-versa? and: the challenges of Mobile channels for banks

L-F Pau

ERS-2004-015-LIS

http://hdl.handle.net/1765/1163

Simulation-based solution of stochastic mathematical programs with complementarity constraints: Sample-path analysis S. Ilker Birbil, Gül Gürkan and Ovidiu Listeş ERS-2004-016-LIS

http://hdl.handle.net/1765/1164

Combining economic and social goals in the design of production systems by using ergonomics standards Jan Dul, Henk de Vries, Sandra Verschoof, Wietske Eveleens and Albert Feilzer

ERS-2004-020-LIS

http://hdl.handle.net/1765/1200

Factory Gate Pricing: An Analysis of the Dutch Retail Distribution

H.M. le Blanc, F. Cruijssen, H.A. Fleuren, M.B.M. de Koster

ERS-2004-023-LIS

http://hdl.handle.net/1765/1443

A Review Of Design And Control Of Automated Guided Vehicle Systems

Tuan Le-Anh and M.B.M. De Koster

ERS-2004-030-LIS

http://hdl.handle.net/1765/1323

Online Dispatching Rules For Vehicle-Based Internal Transport Systems

Tuan Le-Anh and M.B.M. De Koster

ERS-2004-031-LIS

http://hdl.handle.net/1765/1324

Generalized Fractional Programming With User Interaction

S.I. Birbil, J.B.G. Frenk and S. Zhang

ERS-2004-033-LIS

http://hdl.handle.net/1765/1325

\footnotetext{
* A complete overview of the ERIM Report Series Research in Management: https://ep.eur.nl/handle/1765/1

ERIM Research Programs:

LIS Business Processes, Logistics and Information Systems

ORG Organizing for Performance

MKT Marketing

F\&A Finance and Accounting

STR Strategy and Entrepreneurship
} 
Learning Opportunities And Learning Behaviours Of Small Business Starters: Relations With Goal

Achievement, Skill Development, And Satisfaction

Marco van Gelderen, Lidewey van der Sluis \& Paul Jansen

ERS-2004-037-ORG

http://hdl.handle.net/1765/1429

Meta-heuristics for dynamic lot sizing: A review and comparison of solution approaches

Raf Jans and Zeger Degraeve

ERS-2004-042-LIS

http://hdl.handle.net/1765/1336

\author{
A Multi-Item Inventory Model With Joint Setup And Concave Production Costs \\ Z.P. Bayındır, S.I. Birbil and J.B.G. Frenk \\ ERS-2004-044-LIS \\ http://hdl.handle.net/1765/1535 \\ The Level Set Method Of Joó And Its Use In Minimax Theory \\ J.B.G. Frenk and G. Kassay \\ ERS-2004-045-LIS \\ http://hdl.handle.net/1765/1537 \\ Reinventing Crew Scheduling At Netherlands Railways \\ Erwin Abbink, Matteo Fischetti, Leo Kroon, Gerrit Timmer And Michiel Vromans \\ ERS-2004-046-LIS \\ http://hdl.handle.net/1765/1427
}

Intense Collaboration In Globally Distributed Teams: Evolving Patterns Of Dependencies And Coordination

Kuldeep Kumar, Paul C. van Fenema and Mary Ann Von Glinow

ERS-2004-052-LIS

http://hdl.handle.net/1765/1446

The Value Of Information In Reverse Logistics

Michael E. Ketzenberg, Erwin van der Laan and Ruud H. Teunter

ERS-2004-053-LIS

http://hdl.handle.net/1765/1447

Cargo Revenue Management: Bid-Prices For A 0-1 Multi Knapsack Problem

Kevin Pak and Rommert Dekker

ERS-2004-055-LIS

http://hdl.handle.net/1765/1449

Real-Time Scheduling Approaches For Vehicle-Based Internal Transport Systems

Tuan Le-Anh and M.B.M. De Koster

ERS-2004-056-LIS

http://hdl.handle.net/1765/1452

Individual Telecommunications Tariffs in Chinese Communities: History as a Mirror of the Future, and

Relevance for Mobile Service Development in China

H.Chen; L-F Pau

ERS-2004-057-LIS

http://hdl.handle.net/1765/1582

Activating Knowledge Through Electronic Collaboration: Vanquishing The Knowledge Paradox

S. Qureshi and P. Keen

ERS-2004-058-LIS

http://hdl.handle.net/1765/1473 
A Grounded Theory Analysis Of E-Collaboration Effects For Distributed Project Management

S. Qureshi, M. Liu and D. Vogel

ERS-2004-059-LIS

http://hdl.handle.net/1765/1448

Collaborative Infrastructures For Mobilizing Intellectual Resources: Assessing Intellectual Bandwidth In A

Knowledge Intensive Organization

R. Verhoef and S. Qureshi

ERS-2004-060-LIS

http://hdl.handle.net/1765/1474

A Phenomenological Exploration Of Adaptation In A Polycontextual Work Environment

P.C. van Fenema and S. Qureshi

ERS-2004-061-LIS

http://hdl.handle.net/1765/1612

Satisfaction Attainment Theory As A Model For Value Creation

R.O. Briggs, S. Qureshi and B. Reining

ERS-2004-062-LIS

http://hdl.handle.net/1765/1450

Diagnosis In The Olap Context

Emiel Caron, Hennie Daniels

ERS-2004-063-LIS

http://hdl.handle.net/1765/1492

A Deterministic Inventory/Production Model With General Inventory Cost Rate Function And Concave Production Costs Z.P. Bayındır, S.I. Birbil and J.B.G. Frenk

ERS-2004-064-LIS

http://hdl.handle.net/1765/1536

On And Off The Beaten Path: How Individuals Broker Knowledge Through Formal And Informal Networks

Rick Aalbers, Wilfred Dolfsma \& Otto Koppius

ERS-2004-066-LIS/ORG

http://hdl.handle.net/1765/1549

Fractional Programming

J.B.G. Frenk And S. Schaible

ERS-2004-074-LIS

http://hdl.handle.net/1765/1610

Introduction To Convex And Quasiconvex Analysis

J.B.G. Frenk and G. Kassay

ERS-2004-075-LIS

http://hdl.handle.net/1765/1611

Multi-Attribute Dispatching Rules For Agv Systems With Many Vehicles

Tuan Le-Anh and René M.B.M. de Koster

ERS-2004-077-LIS

http://hdl.handle.net/1765/1809

Smart business networks: architectural aspects and risks

L-F Pau

ERS-2004-079-LIS

Economic Lot-Sizing Games

Wilco Van Den Heuvel, Peter Borm, Herbert Hamers

ERS-2004-088-LIS

http://hdl.handle.net/1765/1805 
Simple heuristics for push and pull remanufacturing policies

Erwin A. van der Laan and Ruud H. Teunter

ERS-2004-090-LIS

http://hdl.handle.net/1765/1786

Reverse Logistics - Capturing Value in the Extended Supply Chain

Moritz Fleischmann, Jo van Nunen, Ben Gräve, and Rainer Gapp

ERS-2004-091-LIS

http://hdl.handle.net/1765/1806

Genetic Algorithms In Supply Chain Scheduling Of Ready-Mixed Concrete

D. Naso, M. Surico, B. Turchiano and U. Kaymak

ERS-2004-096-LIS

http://hdl.handle.net/1765/1802

Travel Time Estimation and Order Batching in a 2-block Warehouse

Le-Duc en De Koster

ERS-2004-098-LIS

http://hdl.handle.net/1765/1810

The Social Shaping of the early Dutch Management Schools; Professions and the Power Of Abstraction

Peter van Baalen en Luchien Karsten

ERS-2004-099-LIS

http://hdl.handle.net/1765/1817 